\title{
"Vai ter música?": : para uma antropologia das festas juninas de surdos na cidade de São Paulo
}

José Guilherme Cantor Magnani

\section{(2) OpenEdition}

\section{Edição electrónica}

URL: https://journals.openedition.org/pontourbe/1239

DOI: 10.4000/pontourbe.1239

ISSN: 1981-3341

\section{Editora}

Núcleo de Antropologia Urbana da Universidade de São Paulo

\section{Refêrencia eletrónica}

José Guilherme Cantor Magnani, «"Vai ter música?": : para uma antropologia das festas juninas de surdos na cidade de São Paulo», Ponto Urbe [Online], 1 | 2007, posto online no dia 30 julho 2007 , consultado o 28 julho 2022. URL: http://journals.openedition.org/pontourbe/1239; DOI: https:// doi.org/10.4000/pontourbe.1239

Este documento foi criado de forma automática no dia 28 julho 2022.

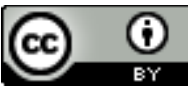

Creative Commons - Atribuição 4.0 Internacional - CC BY 4.0 https://creativecommons.org/licenses/by/4.0/ 


\title{
"Vai ter música?": : para uma antropologia das festas juninas de surdos na cidade de São Paulo
}

\author{
José Guilherme Cantor Magnani
}

\section{Introdução}

1 Ao ser convidado, em 2002, para integrar um grupo de pesquisa formado por lingüistas e historiadores da USP sobre surdos em São Paulo, a primeira reação foi de surpresa, pois pouca ou nenhuma familiaridade tinha com o tema. Quando, porém, me foi explicado o motivo do convite, contribuir com o enfoque antropológico - e em especial com o da antropologia urbana - a uma pesquisa já em andamento, que incluía descrição da língua de sinais brasileira, LIBRAS (por parte dos lingüistas) e registro de histórias de vida (por parte dos historiadores), a proposta começava a fazer sentido. 0 pedido era para identificar a rede de sociabilidade dos surdos na cidade, a partir das categorias de pedaço, mancha, trajeto, circuito utilizadas em pesquisas do Núcleo de Antropologia Urbana. 0 mês em que ocorreu o convite também teve seu papel nos rumos em que essa participação se deu. Era época das festas juninas que tomam conta de escolas, instituições, associações de bairros, paróquias, clubes, etc. e a pergunta que se colocava era: as escolas e associações de surdos também promovem essas comemorações? $\mathrm{E}$ outra indagação, inevitável, logo veio à tona: festa junina de surdo tem música?

2 Para quem havia estudado diferentes formas de lazer na cidade, o estudo das festas não apenas é um recorte obrigatório como ademais constitui sempre uma via de acesso privilegiada para o entendimento das regras que estão na base de redes de sociabilidade. Neste caso, além de ser uma boa opção, a novidade do tema prometia novos desafios. Antes, porém, de retomar as etnografias realizadas e seguir as pistas suscitadas pela indagação acima, faz-se necessário apresentar e desenvolver algumas questões prévias. 


\section{Surdo ou deficiente auditivo}

3 Convém começar com a básica e didática distinção entre a expressão "deficiente auditivo" e o termo "surdo", haja vista a confusão que ainda se faz entre eles mesmo no campo específico dos estudos sobre surdos, agravada pela suposição de que a primeira é mais "politicamente correta" que o segundo. Apesar de estabelecida e aceita em determinadas áreas do conhecimento e instituições voltados para esse tema, a distinção acima apontada não parece suficientemente difundida e reconhecida para além de um círculo ainda bastante reduzido de especialistas. No entanto, é uma distinção que delimita o campo onde a questão será colocada e trabalhada e define as ferramentas que serão utilizadas: ou se trata de uma questão afeita à patologia, de falta ou perda de uma capacidade natural, a ser tratada com os instrumentos apropriados para corrigi-la, talvez amenizá-la; ou, ao contrário, trata-se de um sinal distintivo, capaz de agregar pessoas que se reconhecem de alguma forma vinculadas entre si pelo fato de se comunicarem por uma modalidade - a gestual-visual - diferentemente do que ocorre com a imensa maioria dos usuários da modalidade predominante, auditivo-oral. Assim, ainda que no senso comum "deficiente auditivo" e "surdo" sejam tomados como sinônimos ou como índices de grau, eles apontam para campos de reflexão, atuação e atitudes diferentes. Se na área das ciências da saúde, por exemplo, esta condição é predominantemente encarada como uma falta, nas ciências humanas e sociais (lingüística, história, antropologia, pedagogia, ciências cognitivas e da mente) a tendência é encará-la sob o ângulo de uma marca distintiva, geradora de formas de comunicação, relações, valores, práticas e comportamentos específicos ${ }^{1}$. Essa dicotomia atravessa todo o campo - estudo, pesquisa e atuação - abrangendo os mais diferentes atores (inclusive os próprios surdos) e instituições voltadas para tratamento e ensino, políticas públicas, legislação, produção e comercialização de equipamentos, etc. e sugere a necessidade de, inicialmente, buscar estabelecer mais claramente as necessárias distinções.

No campo em que a essa condição é encarada como patologia, considera-se população surda o conjunto de pessoas portadoras de uma disfunção especifica, a ausência ou perda da função auditiva classificada de acordo com o grau da afecção (profunda, severa, progressiva, lateral, pré-linguística, etc.), constituindo conjuntos de pacientes que são objeto de tratamento e estratégias diferentes. No outro campo, porém, o grupo de referência é constituído com base nas relações que seus integrantes estabelecem entre si, tendo em vista que simbolizam e se comunicam através de outras modalidades (principalmente a gestual-visual) que não a dominante (auditiva-oral). Neste caso, as distinções que se fazem são de outra ordem, e os termos habitualmente utilizados são "comunidade surda", "cultura surda", "mundo surdo", "minoria lingüística", "identidade surda" etc.

Muitas dessas expressões são categorias que pertencem ao campo das ciências humanas e sociais onde são objeto de uma reflexão sistemática e que, para evitar ambigüidades, imprecisões e assim torná-las operativas precisam ser levadas em conta e retomadas à luz das matrizes em que surgiram e foram desenvolvidas.

6 Esses campos de reflexão e pesquisa estão afeitos aos enfoques, entre outros, das áreas da Lingüística, História, Pedagogia e Antropologia, e seu propósito é encarar as questões relativas aos surdos - língua, cultura, aprendizagem, socialização, etc - com a 
complexidade que apresentam e estabelecer pontos de contato com outros domínios do conhecimento.

7 Entre aquelas áreas, a lingüística é uma das que tem apresentado maiores avanços e não é por acaso: a forma de comunicação e sua incidência no aprendizado dos surdos desde muito tempo têm colocado em pauta o tema da língua de sinais. Sem ir muito longe deixando de lado a antiguidade clássica e as referências a esse tema até nos diálogos de Platão - desde o século XVI a questão divide os especialistas entre oralistas (que submetem os surdos a longos e penosos exercícios articulatórios com o objetivo de torná-los usuários da língua oral) e os sinalistas que reconhecem que os surdos se comunicam melhor e mais eficientemente por meio do sistema de sinais. Na França, foi o abade Charles M. de l'Epée, criador da primeira escola pública que usava sinais, em 1760, quem estabeleceu as bases de um processo de reconhecimento, elaboração e aperfeiçoamento dessa modalidade específica de comunicação, processo formalmente interrompido em 1880, no famoso Congresso de Milão, que proibiu seu uso nas escolas públicas².

8 Não há como retomar, aqui, todos os meandros dessa história, com todos os seus embates e conseqüências; o certo é que um experimento de mais de um século foi abortado e passou-se mais outro até que a questão voltasse à cena: é com o trabalho pioneiro de Stokoe (1960) que a língua de sinais deixa de ser encarada como pantomima, conjunto de gestos ou mímica e começa a ser considerada como uma língua dotada de gramática com todas suas partes constitutivas- fonologia, morfologia, sintaxe, semântica etc. Atualmente, em virtude de novas pesquisas (Klima \& Bellugi, 1979; Liddell \& Johnson, 1989; Liddell, 2003, etc.) já não há dúvidas, por parte dos lingüistas, sobre o estatuto da língua de sinais como língua e não como mero código ou linguagem.

9 Um dos pressupostos lingüísticos da própria definição de qualquer língua "natural" é que esta surge e se desenvolve espontaneamente no seio de uma comunidade de falantes. No caso dos surdos, qual é sua comunidade? Eles não têm um território seu e, com exceção da famosa ilha Marta's Vineyard, em Manhattan, não se conhece uma base territorial - país, aldeia, bairro - só de surdos, de forma a assegurar a necessária continuidade e co-presença de falantes nativos ${ }^{3}$. E na população mundial, em torno de $95 \%$ dos surdos nascem de pais ouvintes, o que não lhes assegura condições de uma primeira socialização em contato com a língua de sinais e com a chamada cultura surda.

10 Assim, é de se perguntar que tipo de comunidade eles formam, e aqui já entra a Antropologia, posto que este é um tema clássico de sua reflexão ${ }^{4}$. A própria língua de sinais, aliás, já fora objeto de interesse nos primórdios da disciplina, como se pode comprovar no trabalho de E.B.Tylor, Researches into the early history of mankind (1874), interesse que foi prejudicado pela desvalorização oficial e formal por parte do Congresso de Milão de $1880^{5}$.

\section{Comunidade e cultura: categorias nativas ou analíticas?}

11 Assim, comunidade surda - e também cultura surda, identidade surda, minoria lingüística, mundo surdo, etc.- é empregada freqüente e indistintamente nos mais variados contextos (acadêmicos, políticos, da vida cotidiana) e na maioria das vezes 
com alcances e entendimentos muito diferentes. Na literatura sobre surdos ${ }^{6}$, aparece quase sempre sem maiores explicitações ou como se tivesse um significado unívoco, aceito de forma inconteste, transparente. É o que ocorre, por exemplo, em Skliar(2001, p.6, passim) Sacks (2002, p. 9, passim), Wilcox \& Wilcox (2005, p. 64, 65), entre outros. Uma exceção é Carol Padden (1989), autora que se preocupa em definir o que entende por comunidade: a forma como o faz, entretanto, é reveladora das dificuldades em incorporar um termo provindo de outra área; por isso, vale a pena apresentar seu argumento.

12 Após reconhecer que "unfortunately there is much disagreement among anthropologists and sociologists about what constitutes a 'community' (p. 3) segue a indicação de um autor, George Hillery o qual , depois de avaliar 94 diferentes definições (sic) identifica três pontos comuns a todas elas:

"A community is a group of people who shares common goals and cooperate in achieving these goals; occupies a particular geographic location; has some degree do freedom to organize the social life an responsibilities of its members". (idem, ibidem).

13 Padden propõe, a partir daí, sua definição de comunidade surda: "A deaf community is a group of people who live in a particular location, share the common goals of its members and in a various ways, work toward achieving these goals." (idem, p.5). A autora discorre também sobre cultura surda e todo seu ensaio é objeto de uma leitura crítica de um lingüista, Graham Turner (1994) que, com base em trabalhos de Giddens, Featherstone, Geertz, Street, entre outros, salienta o que denomina de caráter de checklist embutido nas definições de Padden de comunidade e cultura. Ele próprio, entretanto, ao optar por uma perspectiva que incorpora a idéia de cultura as-a verb (no sentido de que cultura não se refere a estados, mas a processos) articulando-a ao conceito gramsciano de hegemonia, não escapa a um certo ecletismo ${ }^{7}$. Já Lane, Hoffmeister e Bahan (1996) descartam "comunidade surda" por considerarem muito inclusivo e preferem a expressão "mundo surdo", restringindo-o apenas àqueles que usam a língua de sinais e se identificam com a cultura surda.

Não se trata de verificar se, neste ou naquele caso, o emprego desses termos está correto ou não; o interesse é, inicialmente, considerar todos eles como usos "nativos", fazendo, porém, as devidas distinções entre um uso descritivo e outro, com pretensões mais analíticas; para tanto, faz-se necessário submeter as categorias a um escrutínio e assim poder avaliar seu rendimento. A proposta, portanto, é mostrar que as ambigüidades presentes nos vários usos nativos são pistas valiosas, reveladoras de nuanças que é preciso antes ressaltar do que homogeneizar; no entanto, transpostas para o plano analítico de forma a-crítica, tais termos, com essas ambigüidades, não contribuem para o entendimento; ao contrário, confundem ou reforçam noções do senso comum.

O estudo dos usos nativos desses termos depende, entretanto, de uma análise de contextos discursivos específicos e demanda, evidentemente, trabalho mais exaustivo com base em corpus consistentes; da mesma forma, verificar seu rendimento como categorias analíticas exige uma discussão teórica mais alentada.

O que segue é uma primeira aproximação e convém começar com "comunidade" - é o termo que mais aparece, tanto em textos acadêmicos como no discurso de militantes do movimento social surdo, de religiosos, professores e na fala do dia-a-dia, com as mais diversas abrangências: a comunidade surda brasileira; a comunidade surda paulistana; 
a comunidade surda da Igreja Batista; a da paróquia N. S. Aparecida; a comunidade surda usuária da língua de sinais; a comunidade surda como um segmento na população dos "portadores de necessidades especiais" e assim por diante.

Trata-se de um uso empírico, ora com conotação territorial, ora política, coloquial e até étnica.

Para melhor apreciar as diferenças e alcances desses usos, vale a pena retomar o ambiente da discussão inicial, na sociologia, desse conceito. E a despeito das críticas que possa receber no campo das ciências sociais, e das múltiplas re-leituras pelas quais vem passando, é possível reconhecer no termo comunidade uma questão de fundo que já estava em seu contexto de origem e que pode explicar porque é tão amplamente utilizado, nas mais variadas circunstâncias e com os mais diferentes alcances. Como se sabe, esse conceito vem sempre associado a outro, sociedade, com o qual forma a clássica polaridade: comunidade versus sociedade. 0 contexto original da discussão é o da passagem do assentamento rural tradicional para a cidade moderna:

"Segundo Tönnies, esquematicamente, comunidade é marcada pelos laços de sangue, relações primárias, consenso, rígido controle social; sociedade, ao contrário, caracteriza-se pela presença de relações secundárias, pela convenção, anonimato, troca de equivalentes. Por meio dessa oposição, o autor descreve a transformação de uma forma tradicional de vida sob a influência de uma economia predominantemente baseada na troca: de uma Europa paroquial e agrária para uma sociedade cosmopolita e comercial." (Magnani, 2000, p.22)

19 Esta distinção está presente, de uma forma ou outra, na reflexão de outros autores mais ou contemporâneos mas de orientações diferentes como Émile Durkheim, Georg Simmel, Max Weber e os da Escola Sociológica de Chicago. Ainda que as nuanças e contextos do uso dessa dicotomia sejam diferentes e historicamente datados, mantémse constante a distância relacional entre os termos: enquanto um aponta para a proximidade dos contatos e para o caráter direto e personalizado das relações, o outro ressalta a formalidade, a presença de convenções mais universalistas. Mas não se pode definir nenhum dos termos por características intrínsecas, pois seus núcleos de significado se estabelecem dentro da relação, por oposição: o que caracteriza "sociedade", por exemplo, seja no caso de uma pequena associação de amigos de bairro, ou de uma abrangente "Sociedade das Nações", é o caráter formal das relações entre os membros, o papel da hierarquia, das instâncias decisórias, a listagem de direitos e deveres definidos por estatutos e regimentos, etc.

E quando se fala em "comunidade" em termos genéricos o que se evoca é também a marca de origem: proximidade, presença de relações face-a-face, seja por contigüidade espacial, (no trabalho, no bairro, na instituição) ou por afinidade de propósitos, crenças e modos de vida compartilhados. O que vincula os membros de uma comunidade seria o reconhecimento desses vínculos e a possibilidade de checar a sua inclusão. Portanto, mais do que organizações sociais concretas, esses termos designam, neste caso, dois tipos-ideais de interação e podem ser encontrados em diferentes arranjos $^{8}$.

21 Por outro lado, eles podem também ser usados como "agregados sociológicos", ou seja, para designar algum grupo concreto. Nessa perspectiva podem ser vistos como recortes empíricos, quantificáveis, referidos sempre a um conjunto de pessoas, ligadas por algum tipo de vínculo e sujeitas a alguma modalidade de normas ou regras. Esta é, porém, a conotação que mais se presta a críticas, como a de George Marcus (1991), sobre o emprego de "comunidade" nas pesquisas antropológicas. 
22 Este autor afirma que é preciso repensar a noção desse conceito tal como foi estabelecido e utilizado em determinados contextos da "etnografia realista", em oposição a uma "etnografia modernista", que leva em conta a mudança não apenas das condições atuais dos povos estudados pela antropologia, como as transformações no cenário mundial onde esses povos se inserem. Assim, afirma Marcus, é preciso romper com uma noção de comunidade que, "no sentido clássico de valores, identidade e, portanto, cultura, compartilhados, foi baseado literalmente no conceito de localidade"(Marcus, op.cit. p.204). Prossegue o autor:

As conotações de solidez e homogeneidade relacionadas com a noção de comunidade (seja esta concentrada num local ou dispersa) foram substituídas nos estudos das modernidades, pela idéia de que a produção localizada de identidade uma pessoa, de um grupo, ou até de uma sociedade inteira - não depende apenas e nem principalmente das atividades observáveis concentradas em uma localidade específica, ou em uma diáspora (idem, ibidem).

Como se pode ver, o emprego de "comunidade", nos exemplos acima, tirados da literatura sobre surdos, ora é vago, ora demasiadamente concreto. Em vista dessas limitações, proponho, em contrapartida, valer-me da "família" de categorias (pedaço, mancha, trajeto, circuito, pórtico) que desenvolvi em outros trabalhos (Magnani, [1984]1998, 2000, 2002) e que vem sendo usadas em pesquisas do NAU $(2002,2005)$, mais apropriadas para captar e descrever a dinâmica e os processos do que para propor delimitações estanques, fixar identidades e delimitar lugares.

Apesar de já terem sido discutidas nesses e em outros textos, vale a pena apresentá-las, novamente, mas numa formulação sintética.

Assim,pedaço"designa aquele espaço intermediário entre o privado (a casa) e o público, onde se desenvolve uma sociabilidade básica, mais ampla que a fundada nos laços familiares, porém mais densa, significativa e estável que as relações formais e individualizadas impostas pela sociedade Pessoas de pedaços diferentes, ou alguém em trânsito por um pedaço que não o seu, são muito cautelosas: o conflito, a hostilidade estão sempre latentes, pois todo lugar fora do pedaço é aquela parte desconhecida do mapa e, portanto, do perigo" (Magnani op. cit. p. 116/117).

Manchas são áreas contíguas do espaço urbano dotadas de equipamentos que marcam seus limites e viabilizam - cada qual com sua especificidade, competindo ou complementando - uma atividade ou prática predominante. Esta categoria fora proposta para descrever um determinado tipo de arranjo espacial estável na paisagem urbana, se comparada, por exemplo, com a de "pedaço", mais estreitamente ligada à dinâmica do grupo que com ela se identifica. A qualquer momento, os membros de um pedaço podem eleger outro espaço como ponto de referência e lugar de encontro. A mancha, ao contrário, resultado da relação que diversos estabelecimentos $\mathrm{e}$ equipamentos guardam entre si, e que é o motivo da afluência de seus freqüentadores, está mais ancorada na paisagem do que nos eventuais freqüentadores. A identificação destes com a mancha não é da mesma natureza que a que se percebe entre o pedaço $\mathrm{e}$ seus membros. A mancha é mais aberta, acolhe um número maior e mais diversificado de usuários, e oferece a eles não necessariamente um acolhimento de pertencimento e sim, a partir da oferta de determinado bem ou serviço, uma possibilidade de encontro acenando, em vez da certeza, com o imprevisto: não se sabe ao certo o que ou quem vai se encontrar na mancha, ainda que se tenha uma idéia do tipo de bem ou serviço que lá é oferecido e do padrão de gosto ou pauta de consumo dos freqüentadores. 
27 Trajeto: esse termo surgiu da necessidade de se categorizar uma forma de uso do espaço que se diferencia, em primeiro lugar, daquele descrito pela categoria pedaço. Enquanto esta última remete a um território que funciona como ponto de referência - e, no caso da vida no bairro, evoca a permanência de laços de família, vizinhança, origem e outros -, trajeto aplica-se a fluxos recorrentes no espaço mais abrangente da cidade e no interior das manchas urbanas. É a extensão e, principalmente, a diversidade do espaço urbano para além do bairro que colocam a necessidade de deslocamentos por regiões distantes e não contíguas.

28 Com relação a circuito, trata-se de uma categoria que descreve o exercício de uma prática ou a oferta de determinado serviço por meio de estabelecimentos, equipamentos e espaços que não mantêm entre si uma relação de contigüidade espacial, sendo reconhecido em seu conjunto pelos usuários habituais. A noção de circuito também designa um uso do espaço e de equipamentos urbanos - possibilitando, por conseguinte, o exercício da sociabilidade por meio de encontros, comunicação, manejo de códigos - porém de forma mais independente com relação ao espaço, sem se ater à contigüidade, como ocorre na mancha ou no pedaço. Mas tem, igualmente, existência objetiva e observável: pode ser levantado, descrito e localizado.

A vantagem do uso dessas categorias é que rompem com a necessidade de escolha presente nas formulações dicotômicas. Tome-se a idéia de pedaço, que se apresenta como espaço intermediário entre "casa e rua": enquanto a primeira representa o domínio do privado, é o espaço das relações de sangue, do contato intimo e da segurança, "rua", ao contrário, é o âmbito do público, das oportunidades, dos estranhos e também do perigo. Pelo fato de intermediar os dois domínios, o pedaço apresenta características de ambos, combinando-as, porém, na forma de novas regras: da casa reproduz o ambiente de segurança e, da rua, a possibilidade de contato com pessoas que não estão vinculadas pelos laços de parentesco. Desta forma, o pedaço pode ser considerado uma espécie de transformação, de passagem do âmbito doméstico em direção ao público. É como se, de um lado, a casa se abrisse para fora e, de outro, a rua se tornasse mais acolhedora: a intersecção entre ambos é que permite a particular experiência proporcionada pelo pedaço.

Todas essas categorias apontam para o espaço público e cada uma delas representa uma diferente modulação desse domínio, na paisagem da cidade e de suas instituições. Desta forma, elas conseguem descrever melhor e com mais nuanças a dinâmica da sociabilidade e as alternativas de encontro, troca, afirmação identitária e mesmo situações de conflito propiciadas pela cidade, principalmente em sua escala metropolitana, como é o caso de São Paulo.

\section{Cultura}

Dá-se com o conceito de cultura o mesmo que com o de comunidade, quando empregado nos estudos sobre surdos: faz-se alguma referência ao campo de onde esses conceitos são originários, mas seu uso é esquemático, descritivo e sobretudo político.Assim, para Padden (op. cit.)

"a culture is a set of learned behaviors of a group of people who have their own language, values, rules for behavior and traditions". (p. 4) Depois de afirmar que há muitas comunidades de surdos nos EUA, mas uma só cultura surda americana, com membros que vivem em diferentes comunidades, essa autora define o critério para 
estabelecer quem é surdo: não é a perda da capacidade auditiva que caracteriza uma pessoa como surda, mas se ela se identifica com outros surdos e se comporta como uma pessoa surda. No entanto, "the most striking characteristics of the culture of Deaf people is their cultural values - these values shape how Deaf people behave and what they believe in. (pg. 9)"

Entre esses valores Padden cita a língua, contatos sociais, as histórias que circulam no meio e a literatura sobre surdos, além de uma série de comportamentos distintivos como, por exemplo, o uso do olhar na conversação: diferentemente do que ocorre entre os ouvintes, para os quais não é de bom tom encarar o interlocutor, esse contato é fundamental na performance característica da língua de sinais. É a esse tipo de caracterização que Turner (op. cit.) se refere quando afirma que "the model encourages us to see a simple checklist of criteria rather than any kind of interrelated network of elements" (p. 112).

Lane e outros (1996), por sua vez, no capítulo dedicado à cultura surda, consideram a cultura como os laços que mantêm os surdos juntos: os surdos sentem-se vinculados uns aos outros primeiramente pela língua e por um conjunto de valores e costumes e o "território" onde a grande maioria dos surdos estabelece seus laços e adquirem sua própria língua e cultura é constituído pela rede das escolas residenciais (p. 125). Mais concretamente, detalham os meios e instituições em que se desenvolve a cultura surda: associações atléticas, clubes, organizações políticas, artes (visuais e performáticas), literatura. Por último, examinam duas poderosas - no seu entender - forças no mundo dos surdos: a força unificadora de uma situação de opressão compartilhada, e a força potencialmente fragmentadora da diversidade.

Além do mais, a forma como os surdos se apresentam uns aos outros, conforme relatam Lane e outros, por meio de "cápsulas" de sua história de vida em que condensam informações tais como a escola onde estudaram, pessoas surdas eminentes que conhecem, instituições com as quais mantêm contato, mostram a particularidade de sua "terra nativa"

"For unlike other cultures, Deaf culture is not associate with a single place, a 'native land'; rather, it is a culture based on relationships among people for whom a number of places and associations may provide common ground". (Lane $\mathrm{H}$, Hoffmeister R. and Bahan, B. 1996:5)

Sem dúvida essa é uma interessante observação a respeito da sociabilidade entre os surdos e a categoria de circuito revela-se mais apropriada para descrever o campo por onde os surdos circulam e mantêm seus contatos mais significativos do que a definição habitual de comunidade, seja a genérica, seja a que supõe alguma forma de adscrição territorial mais delimitada. A noção de circuito (com as demais categorias da "família") introduz, ainda, mais claramente, a questão do espaço público, por oposição ao domínio doméstico, e as limitações que este traz para a socialização dos surdos, principalmente quando nascidos de pais ouvintes. Por outro lado, enquanto "cultura surda" e "mundo surdo", nas formulações acima, designam totalidades fechadas que supõem e determinam quem entra e quem sai, quem pertence e quem não pertence, quem está dentro e quem está fora, a noção de circuito estabelece um recorte mais aberto, com várias modalidades de participação e pertencimento.

Essas tentativas de definição do conceito de cultura, entretanto, tal como ocorria com o de comunidade, apenas tangenciam a discussão que é feita no campo da antropologia: não vão além de um nível descritivo, pragmático. $\mathrm{E}$, da mesma forma como foi mostrado 
a respeito da dicotomia comunidade/sociedade, o conceito de cultura, na antropologia, costuma vir acompanhado de outro termo, compondo o par natureza versus cultura.

Trata-se de uma discussão clássica na disciplina e que abre inúmeras possibilidades para a reflexão sobre surdez. Esta, com efeito, pode ser pensada como uma particularidade inscrita no organismo (na forma de ausência de audição), portanto, no plano da natureza, com implicações no plano da cultura, já que inaugura outras modalidades de simbolização e comunicação. Outra perspectiva de abordagem, menos convencional, é tomar a surdez não simplesmente como um dado "de natureza" mas com uma construção social e histórica, resultado da ação de múltiplos actantes disciplinas científicas, saberes médicos, instituições religiosas, disposições legais, tecnologias, etc. Neste caso, as análises e propostas desenvolvidas por Bruno Latour (2005) podem ser de proveito para um enquadramento inovador, assim como o conceito de "biossociabilidade" de Paul Rabinow (1999), que pode também constituir uma contribuição para enriquecer o debate e ampliar o horizonte de análise.

Em suma, tendo em vista esse panorama, pode-se considerar que a questão da surdez traz para o campo da reflexão e pesquisa antropológicas um tema e um conjunto de atores sociais - habitualmente tratados na área das ciências da saúde sob o foco da patologia, anormalidade, deficiência. - que podem ser encarados numa outra perspectiva: a partir do ponto de vista das diferenças que se estabelecem no interior do próprio universo dos surdos (que não é homogêneo) e também problematizar o uso nativo da expressão mundo dos ouvintes, (o "outro" dos surdos) também postulado como um bloco homogêneo. Em suma, como já foi afirmado, em vez de encará-los sob o prisma da falta, cabe assumi-los da perspectiva da marca.

A estratégia de pesquisa de campo começou pela área do lazer, levando-se em consideração não apenas a linha de trabalho seguida em trabalhos anteriores, com a qual tenho familiaridade, mas também a importância que os surdos dão a atividades como esporte, teatro, atividades religiosas, festas, cerimônias - justamente porque abrem um rico e constante espaço de encontro e de trocas, crucial para a constituição do seu circuito.

Vale então a pena, agora, passar ao relato de experiências de campo que pela primeira vez mostraram algumas pistas para identificação das redes de sociabilidade dos surdos em contextos de lazer na cidade de São Paulo.

\section{"Festa no Pedaço dos Surdos": um relato de campo}

Image 100000000000016A00000117215A6EEE.jpgA participação nas festas juninas de surdos na cidade de São Paulo, em 2002, foi considerada como o início da presença da etnografia nesse campo multidisciplinar de estudo e antecedida por uma série de questões. A primeira era avaliar as condições de realização da pesquisa etnográfica num campo temático novo, principalmente sob a ótica do lazer e da sociabilidade, recorte previamente escolhido para direcionar a observação; a segunda, se seria possível conduzir um "olhar de perto e de dentro" (Magnani, 2002) ainda sem qualquer competência no manejo da língua nativa, a língua de sinais, e sem conhecimento do que se convenciona chamar de "cultura surda". Por outro lado, esse mesmo desconhecimento era visto como o responsável por uma das condições clássicas de realização da pesquisa etnográfica, que é o estranhamento: para quem é introduzido pela primeira vez num meio que lhe é estranho, tudo é significativo, nada pode ser 
previamente hierarquizado numa escala de valores entre o insignificante e o relevante: tudo é digno de observação e registro. Com o tempo, esta condição vai cedendo lugar a uma maior familiaridade com o meio, situação que apresenta ganhos (e perdas) específicos, mas em outra etapa da pesquisa.

Inicialmente, cabe uma apresentação das características comuns dos quatro espaços da observação, feitos pela primeira vez em 2002: ADEFAV (Cambuci), DERDIC (Vila Clementino), Instituto Santa Teresinha (Saúde) e EMEE Helen Keller (Aclimação).

Todas as festas eram promovidas por instituições, e instituições para surdos e não de surdos. Duas delas, Adefav e Derdic, são instituições voltadas para a capacitação e reabilitação: a primeira, Adefav, trabalha com surdos, surdos-cegos e múltiplos deficientes sensoriais; a segunda, vinculada à PUC/SP, é especializada em distúrbios da audição, voz e linguagem. As duas últimas são instituições de ensino para surdos.

Todas as festas eram juninas, isto é, inseriam-se num ciclo festivo de ampla difusão, tanto nos grandes centros como em cidades pequenas e ambientes rurais no país, de norte a sul, apresentando um "roteiro" básico e performances já estabelecidas: barraquinhas para venda de comidas e bebidas típicas, uso de roupas e adereços para caracterizar o personagem "caipira", além de brincadeiras e folguedos, entre os quais a fogueira e a quadrilha.

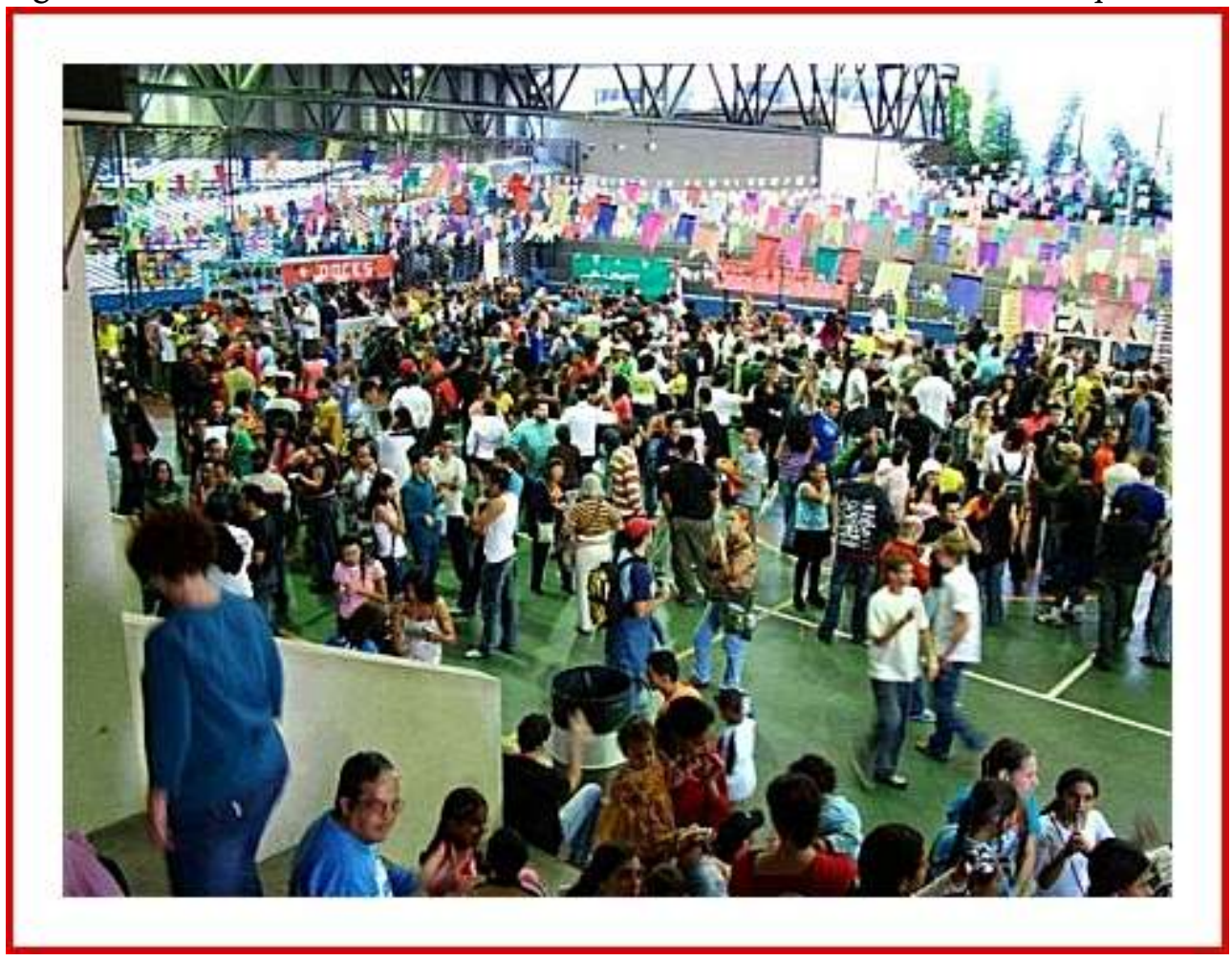

A música é elemento constitutivo da festa e, se pode parecer alheia e despropositada num encontro de surdos, não o é enquanto parte estruturante desse tipo específico de comemoração. Ouvintes - pais, parentes e amigos de surdos - também desfrutam da festa, o que mostra serem esses eventos pontos de encontro mais amplos, colocando em contato diversas categorias de pessoas: não se trata de guetos, mas de espaços alargados de encontro e trocas.

O ambiente geral de todas elas era de muita animação, como acontece nas demais festas juninas que se multiplicam na cidade nessa época do ano. No caso dessas festas em 
instituições voltadas para as pessoas surdas, porém, um elemento diferenciador era que o público-alvo aparecia como mais importante que a inserção espacial: enquanto festas juninas de bairro ou escola geralmente congregam pessoas ligadas por vínculos de proximidade territorial ou institucional, nas de surdos percebia-se uma freqüência dada em função da condição de surdos; pude notar, no pouco tempo de convívio, vários rostos que estavam em quase todas as festas: é como se houvesse um calendário que os surdos conhecem e freqüentam, seja qual for o lugar ou instituição onde ocorram.

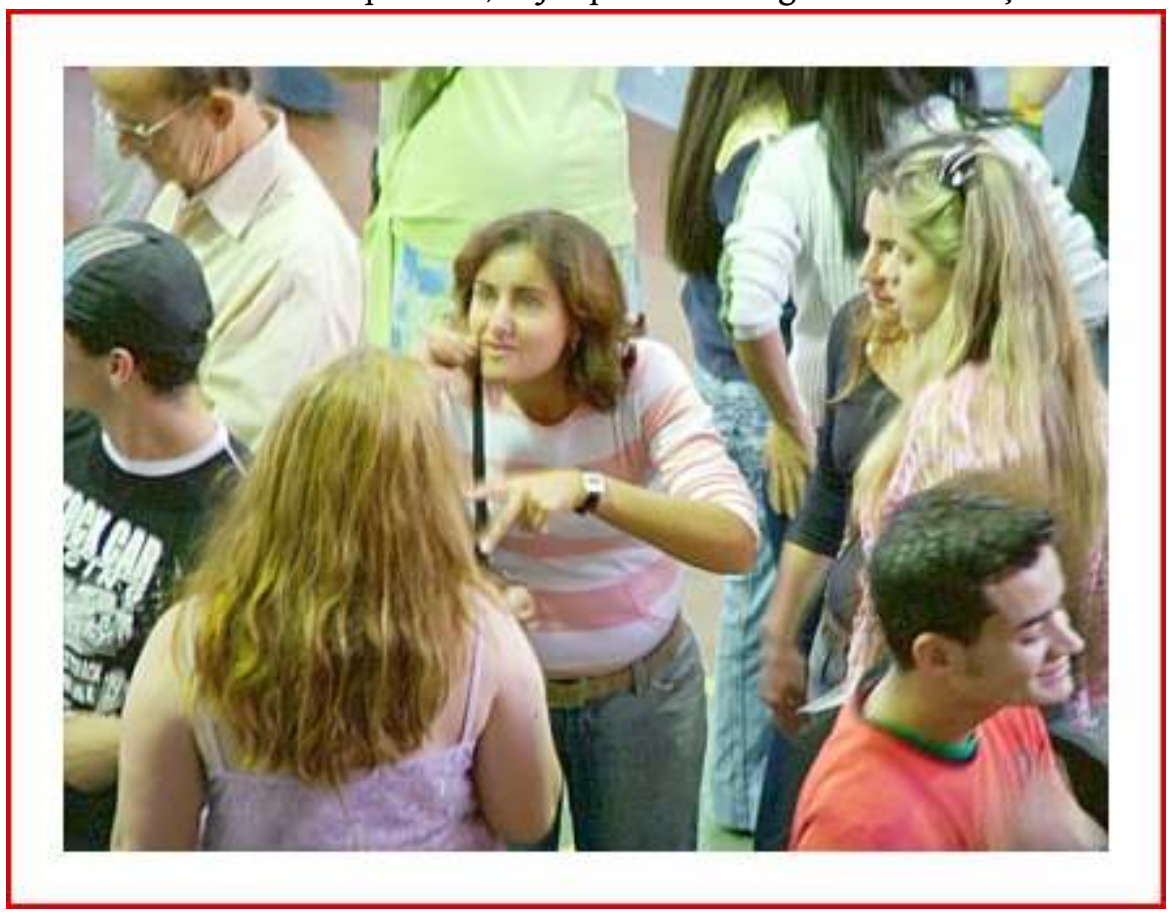

Essas festas, conquanto constituam momentos de celebração e encontro de pessoas surdas qua surdos, permitem encontros e trocas entre elas nas suas diferenças, seja de classe social, escolaridade, origem, local de moradia e vizinhança: é como se pudessem apreciar, para além da condição comum que as une, as diferenças entre elas, o que as torna interessantes umas em relação às outras; mas também abrem espaço para o afloramento de atritos, divergências. Propiciam, ainda, intersecção pública com o universo dos ouvintes, mas em condição de superioridade em relação a eles, a despeito da dominação exercida por suas instituições, no dia-a-dia; ao menos ali, no momento da festa, os surdos eram mais numerosos, comunicavam-se em sua língua, exibiam seus estilos e posturas corporais características. Os ouvintes eram - fato raro - minoria, e atuando no papel de coadjuvantes. A seguir, trechos do caderno de campo das duas primeiras festas:

Na Adefav, a festa, no cair da tarde do dia 7 de junho de 2002, era na rua, em frente à sede da instituição. Em torno do nº 253 da rua Lacerda Franco, distribuíam-se as barracas, as mesas e cadeiras e o pequeno palco. De certa forma o espaço assim constituído era uma extensão das dependências da associação, a qual servia de retaguarda e oferecia a infra-estrutura básica para a festa: depósito, banheiro, cozinha, refúgio, camarins...Como a instituição atende, além de surdos, crianças com múltiplas deficiências, essa proximidade garantia o fornecimento de cuidados extras para seu público específico. A festa lembrava a situação descrita no texto "Quando a rua vira casa", ou, colocando desde outra perspectiva, mostrava a casa crescendo, incluindo o espaço da rua. $\mathrm{O}$ fechamento de uma ou várias vias públicas é uma estratégia bastante comum em comemorações de bairro, incluindo até experiências mais amplas, como as conhecidas "feiras de vila" (Vila Pompéia, Vila 
Madalena e outras). Desta forma a rua, no contexto da grande metrópole, em determinada ocasiões é novamente apropriada pelos moradores de forma integral, podendo-se andar por ela sem perigo, desfilar, apreciar, exibir-se, ir de um canto para outro.

Uma experiência singular foi o contato com Cláudia Sofia, uma moça surda e cega que freqüenta na Adefav e ali atua. Após observar sua forma de comunicação com outro surdo cego, pedi a uma das diretoras da instituição para entrar em contato com ela, no que fui prontamente atendido. A experiência foi marcante, e sugeriume uma série de desdobramentos. A diretora contou-me que havia outra moça, também surda e cega, que atuava em outro "circuito": por ser evangélica, não freqüentava festas e assim procurava contato com pessoas na sua condição em templos e igrejas.

Sua modalidade de comunicação é denominada "Tadoma", método de comunicação especifica para surdos-cegos em interlocução com ouvintes-falantes, pois é obtida pela vibração dos órgãos fono-articulatórios. Foi desenvolvido pela professora de duas crianças, Tad e Omã (daí a denominação) que ficaram surdas-cegas em decorrência da síndrome de Usher, tipo de surdez congênita seguida ou não de perda de visão a qual ocorre, geralmente, em idade mais avançada. Trata-se de uma forma de comunicação em que a pessoa surda-cega, por meio do tato, decodifica a fala de seu interlocutor, colocando a mão no rosto de quem fala de forma que o polegar toque, suavemente, seu lábio inferior e os outros dedos sintam a vibração das cordas vocais. Contudo, entre surdos-cegos usuários de Libras, a forma de comunicação mais habitual é denominada "Libras tátil". Em ambos os casos, a postura e movimentação dos corpos configuram uma performance muito particular. Este fato merece um relato à parte, e entra aqui apenas por ter ocorrido no contexto daquela festa. Sofia foi uma das pessoas que voltei a encontrar na festa seguinte, no Instituto Santa Teresinha, a próxima a ser descrita:

"O Instituto Santa Teresinha convida para a tradicional festa junina que se realizará no dia 15 de junho das 16 às 22 horas, na rua Jaguari, 364, na quadra de esportes da OEMAR. O comprador deste convite concorrerá ao seguinte prêmio: 1 máquina fotográfica digital - clone."

O meu ingresso, que custou $\mathrm{R} \$ 3,00$, era de número 1.529; como cheguei em torno das 20 h00, ele pode ser tomado como um indicador da quantidade de pessoas que até aquele momento tinham ido ao evento. E essa foi, de fato, a experiência mais marcante. Em contraste com o clima mais tranqüilo e familiar da festa da Adefav, aqui, o ambiente era agitado, as pessoas estavam bastante animadas e realmente havia muita gente. Os ônibus nas imediações atestavam que tinha vindo gente de outras cidades e até de outros Estados. Tive a sensação de estar entrando numa "comunidade em festa", numa aldeia em efervescência: nunca tinha visto tantos surdos juntos, e essa densidade permite percepções vívidas e ricas de suas formas de sociabilidade, de suas particularidades como grupo diferenciado.

Image 100000000000017B00000127AA4D70FC.jpg

Como um estrangeiro, caminhava no meio deles apreciando as rodinhas de conversa, dos grupos de amigos, os casais, as conversas, a forma como estavam vestidos; pelo fato de não dominar a língua de sinais, não me prendi a nenhum grupo, nem procurei decifrar o que diziam; interessava-me, nesse momento, fazer uma imersão nesse ambiente novo, cujo código básico de comunicação me era estranho. Como eram as regras de etiqueta? Pode-se passar no meio de uma roda de conversa? Como pedir desculpas por um esbarrão? Solenemente ignorado por todos, restavam-me outros códigos e outros planos de observação, sendo obrigado a apurar o olhar, já que os significados não podiam provir por intermédio do som. São raros esses momentos, na experiência etnográfica: a prática mostra que aos poucos vai-se adentrando no universo do outro, que acaba perdendo essa capacidade de maravilhar, e termina tornando-se familiar ao observador ${ }^{10}$. 


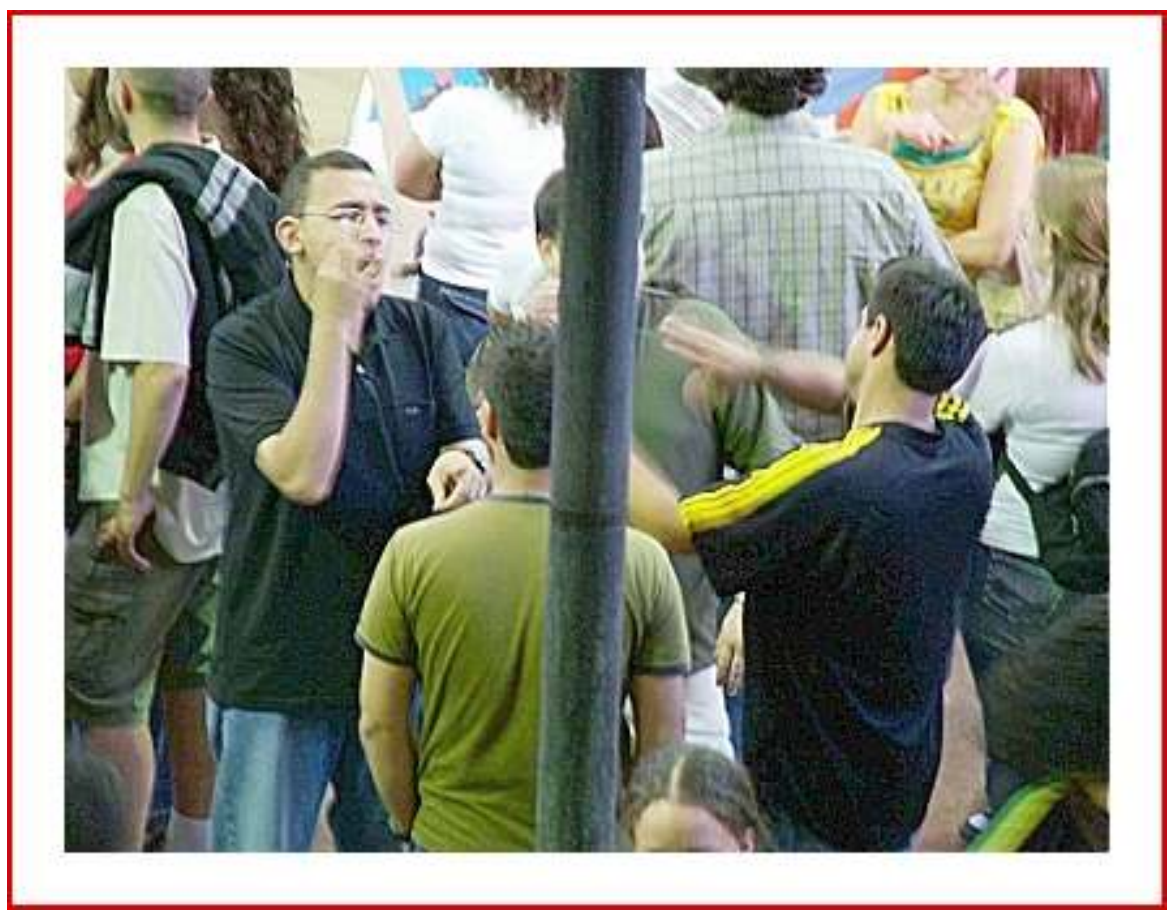

Num determinado momento subi os degraus da arquibancada que fica diante da quadra onde rolava a festa e, lá de cima, tive acesso a um espetáculo realmente inusitado: uma disparidade entre a multidão e o barulho que deveria estar fazendo, numa festa de ouvintes; em contraste, havia um fervilhar de mãos numa espécie de frenética pantomima, ao menos aos olhos de um leigo. Em termos plásticos e coreográficos o espetáculo era realmente impressionante, e me perguntei se o efeito do barulho, da algaravia, da música no último volume sobre um ouvinte seria da mesma ordem, em termos até de uma experiência extática, ao efeito produzido pelo "mar de mãos", sobre uma pessoa surda ${ }^{11}$.

Image 10000000000001CF000001671F8E4C5F.jpg

Ganhei a revista "Sentidos- a inclusão social com alto astral", recebi prospecto e explicações sobre as vantagens de determinada marca de aparelho telefônico para surdos, conversei um pouco com Cláudia Sofia, encontrei uma participante do nosso grupo de pesquisa (Lia) e entrei nas filas das barraquinhas de bebidas, sanduíches, etc. para comprar tíquetes. Já na rua, indo embora, ganhei um folheto intitulado "Por que eu", de uma igreja evangélica, com considerações a essa pergunta, dirigida a diversas pessoas com doenças graves e defeitos físicos. A resposta, no folheto, consistia em reconhecer os próprios pecados e esperar a graça de Deus para suportar a dor e o sofrimento. Nada mais distante do que o clima reinante na festa a 


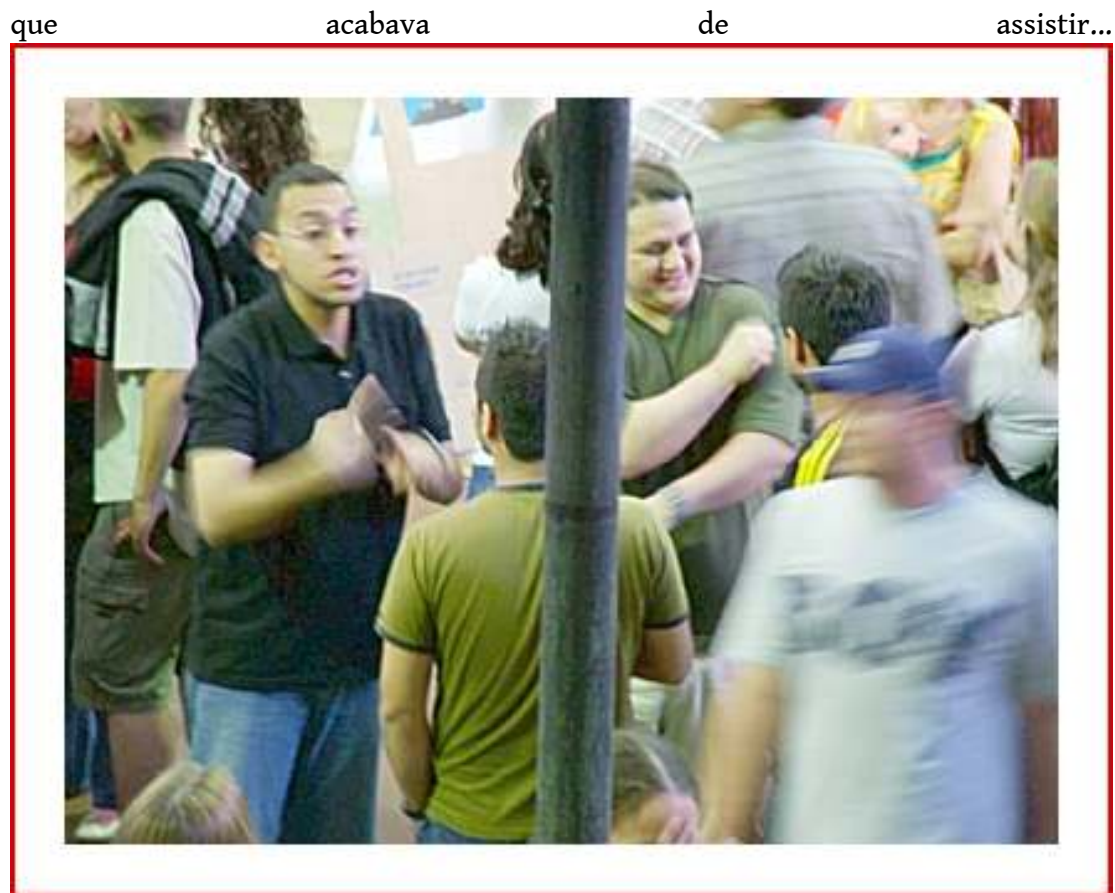

As outras duas festas observadas ocorreram, respectivamente na DERDIC (Vila Clementino) e na EMEE Helen Keller (Aclimação). A primeira, cujo ingresso era mais barato, um real, foi no dia 22/06/2002, na rua Dra. Neyde Aparecida Sollito, no 435. Apesar de ter chegado, com Valéria, já quase no fim da festa ainda consegui comprar uma latinha de cerveja, para entrar no clima e poder circular à vontade. De novo, lá estava Lia que nos apresentou a algumas pessoas importantes do meio. Não deu para avaliar a animação dessa festa, mas os grupos remanescentes manifestavam o mesmo padrão de intensidade de comunicação entre si; também era mais visível presença de familiares acompanhando os alunos; numa das dependências da escola, contígua à quadra, estava ocorrendo um bingo.

$\mathrm{Na}$ escola Hellen Keller, rua Pedra Azul, no 314, a festa foi no dia 29 de junho e o ingresso também de R\$1,00 Carin, Danilo e César também estavam presentes. Como no Instituto Santa Teresinha, havia muita gente, muita animação e a circulação era intensa. Na quadra poliesportiva rolava uma partida de futebol e pude apreciar a já comentada disposição física e envolvimento dos surdos com o esporte. Uma brincadeira comum em festas juninas, que consiste em prender alguém numa cadeia da qual só se sai mediante algum tipo de pagamento, era feita com, digamos, muito entusiasmo e...vigor físico. Numa sala ao lado, já nas dependências da escola, havia computadores com documentários relativos a personagens importantes na história dos surdos, suas conquistas, e um vídeo com noticiário feito por e para surdos, produzido na própria escola.

Das observações e impressões obtidas no decorrer do trabalho de campo nessas festas, algumas considerações gerais, pistas e perguntas para futuras incursões podem ser anotadas. Em primeiro lugar, chama a atenção a faixa etária dos participantes: eram, em sua grande maioria, jovens, entre 14 e 30 anos, aproximadamente. Há que se perguntar se esta predominância é devida ao fato de se tratar de festas em ambiente escolar e se surdos mais velhos oferecem ou não maior resistência à participação em eventos públicos. Poder-se-ia investigar se em outros eventos - religiosos, de ensino, cultural, etc. - mantém-se essa predominância juvenil. Teria algo a ver, também, com uma melhor performance na língua de sinais?

Outra questão a ser aprofundada é com relação às origens e posições de classe, além de local de moradia. Haveria, por exemplo, alguma correlação negativa entre melhor 
desempenho na língua de sinais e nível de renda e/ou escolaridade? Em outros termos: pessoas surdas de classes sociais mais altas tenderiam a receber treinamento com vistas à oralização, usariam português sinalizado, etc. diferentemente de surdos de camadas mais pobres, aos quais não restaria outra alternativa para comunicação senão a língua de sinais? Neste caso, qual seria seu grau de generalidade e abrangência? Não poderia, neste caso, restringir-se a uma espécie de "dialeto de periferia"? Evidentemente, esta é uma questão também pertinente à área da sociolingüística, cuja abordagem vai além do âmbito de uma pesquisa especificamente em festas e momentos de lazer, mas tem a ver com a amplitude do campo de trocas e experiências a que os surdos, em seus diferentes graus, modalidades, nuanças, têm acesso.

Nas festas observadas foi possível notar a presença de grupos familiares mais marcadamente em duas delas: Adefav e Escola Helen Keller. No Instituto Santa Teresinha de ambiente mais cosmopolita, predominavam grupos de jovens. Até onde pude notar, havia representantes de um segmento importante no universo dos surdos, o dos intérpretes, nas festas analisadas. Qual a participação deles, nesse tipo de evento? Estariam eles lá desfrutando, a seu modo, de uma festa, que de certa maneira é também deles? Qual é a rede e os espaços de lazer e encontro dos intérpretes, cujo trabalho (e sem dúvida, valores, interesses, etc.) está ligado a esse universo específico?

Essa incursão a campo realmente mostrou, de forma viva e convincente, a existência de um segmento diferenciado e a presença de um mecanismo particular de elaboração simbólica e comunicação. Uma questão a aprofundar é: qual o estatuto do que é, nesse meio, denominado "cultura surda" e desse instrumento de comunicação, a língua de sinais? Qual é o grau de universalidade que apresentam e de forma absorvem traços, marcas, expressões ligados a círculos de socialização específicos?

Tais indagações, evidentemente, são mais gerais e transcendem a etnografia nos espaços de lazer: apontam para questões de fundo e requerem uma reflexão mais teórica, multidisciplinar e outros recortes de pesquisa de campo. o que, sim, o plano empírico da observação já mostrou é a existência tanto de um núcleo politicamente consistente, formado pelos surdos que se comunicam pela língua de sinais - e que se colocam como referência e interlocutores, por exemplo, de políticas públicas - como de surdos que se aglutinam com base em outros vínculos, do tipo religioso, ou de lazer. É preciso identificar, observar, descrever e analisar as relações, passagens, conflitos e trocas entre esses diferentes pólos de aglutinação.

50 Para tanto a questão da cidade é crucial, em termos estratégicos. Os graus de uso, a formas de mobilidade, a multiplicidade de pontos de encontro, as oportunidades de trabalho, estudo, etc. oferecidas pelas diversas escalas urbanas é que vão determinar um maior ou menor campo de trocas, permitindo construir, fortalecer e exibir marcas de identidades que se legitimam na medida em que são assumidas pelos "de dentro" e exibidas para "os de fora". É preciso, pois, identificar os pedaços, os circuitos, os trajetos $^{12}$ que constituem diversas modulações ou gradações do espaço público onde se pode perceber a construção de múltiplas identidades - em contraste com o confinamento do espaço privado, que dificilmente consegue fazer a passagem do estigma, negativo, para a marca de pertencimento, positiva.

51 Foi a partir dessas primeiras experiências que a equipe do NAU voltada para a pesquisa com os surdos teve acesso a outros espaços de encontro e socialização, como os cultos religiosos, congressos, encontros e apresentações teatrais. Em cada um desses contextos, novas pistas se abrem para a reflexão colocando questões novas, que não 
cabe detalhar aqui. Penso que as primeiras incursões nesse terreno abriram um campo novo, desafiador, e que é válido o registro das primeiras impressões, pois logo vão ficando para trás - resolvidas, esquecidas ou subsumidas em outras - à medida que as análises prosseguem e se tornam mais específicas.

Este é o propósito deste artigo, preservar o clima da experiência etnográfica em seus inícios, com suas primeiras indagações. E para completar, um último relato cujo tom de anticlímax os antropólogos conhecem muito bem, mas que deve ser recuperado não como mais um dos "faits divers" que pontuam o trabalho de campo, e sim pelo que pode dizer da especificidade da etnografia.

\section{Festa de Cowboys na Associação dos Surdos de São Paulo}

53 A observação deste evento - que não é propriamente uma festa junina - foi feita na sequiência das anteriores e de certa maneira fecha o primeiro ciclo de participação em festas de surdos. Ocorreu no sábado dia 26/10/2002, na Av. Pedro Bueno, 660 - Pq. Jabaquara (próximo ao metrô Conceição e aeroporto de Congonhas) na Associação dos Surdos de São Paulo.

Conforme o recado deixado por Lia na lista de discussão do Projeto Estudos da Comunidade Surda, o evento teria início às 21 h00 estendendo-se até às 5:00h. 0 site da Associação, porém, apresentava outro horário: início do evento às 17 h00. Tirando uma média, então, resolvi ir às 20 h00 e, mesmo assim, cheguei muito cedo, como logo ficou claro. Havia pouca gente nas imediações; comprei o ingresso (2 reais) numa mesa posta no alto da escada que dá acesso ao sobrado onde está sediada a Associação; não havia nenhuma placa ou indicação. O único momento de comunicação que consegui estabelecer foi com um senhor, já no interior da casa, para confirmar "se era ali a festa". Entendeu minha pergunta (provavelmente pela leitura labial) e respondeu naquela voz característica de surdo oralizado. Depois disso, passei duas horas sentado numa cadeira, olimpicamente ignorado por todos que lá estavam...

O ambiente era simples: tipicamente uma sede de associação, meio clube de bairro, meio centro comunitário com mesas de pebolin, de baralho, uma cozinha, banheiro, cadeiras espalhadas e umas quatro salas. De cowboys mesmo, havia a representação de uma cabeça de boi pendurada no alto de uma parede, alguns cartazes de traço e tema meio infantilizados alusivos ao evento e algumas pessoas com chapéus de vaqueiro. Sentei-me numa das cadeiras colocadas ao longo das paredes no corredor que dá acesso às demais dependências e pus-me a observar os que já estavam e os que iam chegando. De início, umas vinte pessoas das quais 15 eram homens. Foram chegando mais e o número de mulheres aumentou. No começo, as pessoas estavam conversando de forma mais individualizada. Quando saí, às 22 h00, havia cinco grupos formados: 3 dentro da casa, sendo um só de moças; outro monopolizado por um rapaz acompanhado de sua namorada, muito animado; outro reunido numa das salas; uma na escada de acesso e o último já na calçada, em frente à sede. Diferentemente desses grupos, o tempo todo no mesmo lugar, alguns senhores, com pinta de serem "da diretoria", locomoviam-se de um lado para outro, alguns deles atentos ao fogo e aos espetinhos na churrasqueira. A maioria absoluta era de jovens, entre 18 e 30 anos, metade rapazes metade moças, ao 
menos na hora em que saí. Mais ou menos 30 pessoas dentro da casa, 10 na escada, uns 20 fora.

56 A sensação foi, mais uma vez, de estar numa aldeia; só que, desta feita, eu estava não apenas isolado, como nas festas juninas, mas também imobilizado. Não havia ninguém conhecido, o ambiente era menor, e senti-me acuado: estava realmente num pedaço surdo, e não era capaz de manejar a regra básica: a língua de sinais. Senti-me constrangido até mesmo para levantar e comprar algo para comer ou beber e assim, minimamente, participar da festa. Não ocorreu nem mesmo a situação em que alguém chega e pergunta o que é que eu estava fazendo ali - como bem poderia acontecer quando se descobre alguém de fora do pedaço.

57 Num ambiente onde todos se conheciam, os surdos cumprimentavam-se e logo se enturmavam; e eu, cada vez mais me sentindo como um peixe fora d'água. Deram-me até as costas.... mas não senti agressividade, hostilidade e sim indiferença; eu é que não agüentei a pressão: a forma dominante de comunicação era em língua de sinais. Desta forma, não tinha condições de estabelecer qualquer contato nem mesmo para, se interpelado, dizer o que estava fazendo ali. E, pior: se alguém me fizesse a pergunta, que poderia responder? Que estava escrevendo um livro sobre surdos? Fazendo "pesquisa" - principalmente depois de saber quanta desconfiança essa palavra desperta nos surdos? ... Na verdade, eu até que tinha uma historinha pronta, caso fosse interpelado: havia combinado encontrar dois amigos surdos (Alex e Roberto, da universidade) e/ou um intérprete (Ricardo). Mas se o suposto "interrogatório" prosseguisse, e fosse perguntado sobre meu interesse particular em estar ali, não teria uma resposta convincente. Sentia-me fora de lugar, e ignorado: eles estavam na casa deles, no clube deles, entre eles. Esta era uma festa de surdos, para surdos, mas organizada pelos surdos, diferentemente do caso das festas juninas da Derdic, Santa Teresinha, Adefav e Hellen Keller. Aqui não havia ouvintes! Alguns portavam aparelhos, mas a forma dominante de comunicação era através da língua de sinais. De vez em quando passava, bem próximo, um barulhento avião - a Associação fica perto do aeroporto de Congonhas - o qual, evidentemente, só a mim incomodava.

Algumas das pessoas apresentavam certos traços fisionômicos que estou começando a notar quando em contato com um grupo maior de surdos, mas sem ainda poder relacionar com alguma causa específica: seria alguma síndrome em particular? Aparentemente, a maioria era de jovens de classe média baixa, alguns de classe baixa. 0 jovem "falador" e sua namorada estavam bem vestidos, eram muito expressivos, principalmente o rapaz; na sua frente estava posicionado outro casal, ele, atento e participativo, mas a menina era mais retraída. Contei três pessoas com traços nitidamente orientais (uma mulher, dois homens) e depois chegou uma moça, também de origem oriental, acompanhada por outras jovens no meio de um grupo de moças.

Diferentemente das festas juninas, não havia música, talvez porque não havia ouvintes... nem aquele clima de animação geral. o clima era de encontro de pessoas que se conhecem, todos à vontade, em seu pedaço. Percebi ser necessário ter um mínimo de conhecimento da língua de sinais, ao menos para o básico - "sou ouvinte, tenho alguns amigos surdos, fulano e beltrano..."; "por favor"; "desculpe"; "quanto custa tal coisa" etc. E é preciso ter sempre uma historinha à mão, para poder freqüentar e circular em ambientes como este, tipicamente de pedaço - ainda que divulgado numa página da Internet. 
60 Fiquei duas horas de frente para uma parede, vendo de soslaio o movimento de entrada e saída das pessoas e observando-as em suas dinâmicas de encontro e comunicação. Fiquei constrangido para levantar e circular e até mesmo para ler os cartazes e avisos. É verdade que logo na chegada, após sentar-me na fatídica cadeira, caiu um cartaz da parede e dispus-me a recolocá-lo, no que fui ajudado por um dos presentes, devidamente paramentado com um enorme chapéu de vaqueiro. Como faltava um pedaço de fita adesiva, ele foi buscar; pregamos o cartaz e no final foi possível trocar um olhar.... e contemplei, longamente, um aviso que estava logo em frente: "Não jogue lixo no chão, jogue no lugar certo".

Depois disso nenhum dos surdos me dirigiu um olhar sequer, mesmo quando passavam por mim: certamente eu estava fora de lugar; era, logo à primeira vista e de longe, um estranho; eles, ao contrário, estavam em seu ambiente, seu pedaço, à vontade, entre iguais. Não havia possibilidade de contato, a não ser por meio de algum tipo de interpelação, diferentemente de outras situações de pesquisa onde ao menos perguntas de valor "fático" seriam possíveis - onde é o banheiro? Quanto custa o sanduíche? o que vai acontecer agora?

62 A experiência valeu, paradoxalmente, pela absoluta falta de comunicação, pela estranheza mais completa. Se a etnografia sempre permite experimentar a vivência do outro, quem sabe é dessa forma que um surdo se sente quando está no meio de ouvintes que nem ao menos se dão conta de sua particularidade. Comentando minhas impressões dias depois, com Lia, que chegou a essa mesma festa por volta da meia noite, soube que a festa durou mesmo até a madrugada e houve um incidente em que uma menina foi atropelada por uma moto, fato que mobilizou os surdos da festa. Perdi.... que mostra, mais uma vez, que o etnógrafo deve ser o primeiro a chegar e o ultimo a sair, para não deixar passar nada... Mas aos pouco vamos construindo um corpus consistente de festas, a partir do qual será possível identificar sua estrutura mais geral e descrever suas diferentes dinâmicas.

\section{Conclusão}

As festas juninas ofereceram o primeiro contato sistemático com o lazer do surdos e, juntamente com a surpresa e o deslumbramento de um campo novo, trouxeram questões de interesse que apenas começam a ser vislumbradas, como procurou mostrar o artigo, construído com base nas idas iniciais a campo. Se os dois primeiros relatos enfatizam a sensação de descoberta, o terceiro faz o papel de contraponto: aparece como uma espécie de anticlímax, mas na verdade serviu para mostrar uma outra dimensão do chamado encontro etnográfico. Em ambas as situações pode-se identificar o que o que Favret-Saada ([1990]2005) descreve como a condição de "ser afetado": no primeiro caso o antropólogo pôde vivenciar a descoberta de uma nova dimensão até então desconhecida ou nomeada com os termos do senso comum (o surdo como deficiente) ou por meio de sistemas classificatórios de uma determinada área (surdez como patologia); já a segunda situação trouxe o outro lado da situação, permitindo ao pesquisador ter uma idéia de como se sente o surdo quando imerso na sociedade envolvente, o mundo dos ouvintes. 0 final do processo foi perceber que tinha chegado o momento de pôr os pés no chão e reconhecer que pesquisa teria de entrar em outra etapa. Terminara a fase do encantamento, da novidade representada pela descoberta desses novos atores sociais na cidade, até então invisíveis, da vontade de explicar para 
todo mundo a sutileza, por exemplo, da língua de sinais que não, não é pantomima, mas uma língua com sintaxe, morfologia, semântica .... E chegou-se à conclusão, também, que não há como aprofundar a pesquisa sem aprender essa língua!

Com o auxílio de algumas categorias foi possível descrever o cenário das festividades: assim, a noção de pedaço permitiu entender a dinâmica de duas delas, a realizada pela Adefav e a da Associação dos Surdos de São Paulo. Mas havia diferenças: a circunstância de a primeira realizar-se na rua terminou dando-lhe um caráter mais aberto, enquanto na segunda quem não era mesmo do pedaço não se sentia à vontade: os sinais de reconhecimento eram mais estritos. Contudo, nessa mesma Associação (não é muita informação, trazer outra etnografia), em outra ocasião, numa cerimônia de caráter religioso - a entronização de uma imagem católica - ensejou um encontro mais aberto com a presença de ouvintes, surdos oralizados, intérpretes de igrejas neopentecostais, etc. Já a Escola Santa Teresinha constitui o epicentro de uma mancha que inclui a quadra poliesportiva, as ruas adjacentes, os arredores, os bares da vizinhança, as esquinas, os pontos de ônibus, todos tomados por surdos, tanto nas festas, quando sua presença é massiva, como no cotidiano. Derdic e Hellen Keller pertencem propriamente ao circuito pedagógico, mas no período das festas se integram ao circuito das festas juninas e seguem os padrões dessas comemorações; ainda que abertas a participantes alheios à escola (basta comprar o ingresso para entrar) ficam, entretanto, mais restritas aos alunos e seus familiares. É interessante notar essa dinâmica quando instituições específicas do ponto de vista de suas funções (escola, terapia) se transformam e se integram às normas de outro circuito, o festivo, ajustando-se ao calendário de lazer. Como se pode ver, seria difícil, nessa conjuntura, classificá-las como "comunidades" com fronteiras e freqüentadores bem delimitados.

Com relação aos atores, o que poderia parecer um bloco só, indistinto - surdos, em suas festas - na verdade revelou uma notável heterogeneidade. Lá estavam todas as nuanças: surdos usuários de Libras, surdos oralizados, surdos-cegos, implantados, com aparelhos, familiares, professores, intérpretes, pesquisadores, religiosos. Esses atores se conectam, fazem escolhas, percorrem trajetos; em algumas circunstâncias, os que dão o tom são os surdos mais intelectualizados, isto é, aqueles que freqüentam a universidade ou circulam em meios acadêmicos, proficientes em Libras, antenados com questões e eventos do movimento surdo politizado; em outros casos, essas características não tem centralidade e o que importa é o fervor religioso (nas romarias devocionais, por exemplo) quando qualquer modalidade de comunicação é aceita. 0 mesmo ocorre em eventos esportivos, workshops, congressos: mudam a etiqueta, o eixo, reorganizam-se os fluxos. Na já mencionada festa de entronização da imagem de São José, na Associação dos Surdos de São Paulo, em que o padre celebrante usava português sinalizado, havia até intérpretes de igrejas neopentecostais, mas nenhum surdo do circuito "intelectual".

66 E para concluir: afinal, havia música? Sim, nas festas dos surdos que foram objeto de observação, havia música. E muitas outras coisas que a pesquisa apenas começa a descobrir, de interesse não apenas para o entendimento dos surdos e suas instituições, mas da própria cidade enquanto espaço público por onde eles estabelecem seus circuitos e recortam seus trajetos e cuja dinâmica favorece, impede ou amplia as alternativas de encontro, trocas e exercício da diferença, como direito de cidadania. A própria questão de haver ou não música em festas de surdos foi objeto de polêmica nos anos seguintes, pois não é um assunto secundário: envolve, de certa forma, todos as 
noções que foram mencionadas neste artigo: comunidade surda, cultura surda, centralidade da língua de sinais, vínculos com os ouvintes, relações com instituições e políticas públicas. É válida ou conveniente a presença de um elemento que evoca exatamente uma diferença fundamental, que aponta para um "grande divisor" - entre os que ouvem e os que não ouvem? Não seria politicamente incorreta num contexto em que se procura justamente consolidar a especificidade da língua de sinais? $\mathrm{Ou}$, ao contrário, sua presença não poderia trazer à tona outras mediações, facetas e passagens entre aqueles dois pólos?

O que parece ser tão "natural" em qualquer festa revela, assim, aspectos políticos da constituição de atores sociais em sua complexa dinâmica no contexto da metrópole. A pesquisa segue, no Núcleo de Antropologia Urbana, em contato com pesquisadores do Departamento de Lingüística da USP, integrado a um grupo interdisciplinar ${ }^{13}$. A fase atual se caracteriza por estudos mais específicos de temas e objetos identificados ao longo do importante circuito formado por instituições religiosas e suas múltiplas atividades voltadas para os surdos.

\section{BIBLIOGRAFIA}

FAVRET-SAADA, Jeanne. "Ser afetado", in Cadernos de Campo-Revista dos Alunos de PósGraduação em Antropologia Social da USP, ano 14, n. 13, 2005

KLIMA, Edward and BELLUGI, Ursula. The signs of language. Cambridge MA: Harvard University Press, 1979

LANE, H.; HOFFMEISTER, R.; BAHAN. B. A journey into the deaf-word. San Diego, CA; Dawn Sign Press, 1996

LANE, Harlan. When the mind hears: a history of the deaf. Nova York: Random House, 1984.

LATOUR, B. Reassembling the Social: An Introduction to Actor-Network-Theory. Oxford: Oxford University Press, 2005

LIDDEL, S.K. Grammar, Gesture and Meaning in American Sign Language. Cambridge: Cambridge University Press, 2003

LIDDELL, S.K. \& JOHNSON, R.E. "American Sign Language: The phonological base". Sign Language Studies 64,1989

MAGNANI, José Guilherme C. Festa no Pedaço: Cultura Popular e Lazer na Cidade - 1998, Hucitec (segunda edição)

MAGNANI, José Guilherme C. \& TORRES, Lilian de Lucca (org.).Na Metrópole. São Paulo, EDUSP/ FAPESP, 2000

MAGNANI, J. Guilherme Cantor. De perto e de dentro: notas para uma etnografia urbana. Revista Brasileira de Ciências Sociais, ANPOCS, vol 17 No 49, 2002. 
MARCUS, George. "Identidades passadas, presentes e emergentes: requisitos para etnografias sobre a modernidade no final do século XX ao nível mundial".Revista de Antropologia, vol. 34, 1991.

MOURA, Maria Cecília de. O surdo: caminhos para uma nova identidade. São Paulo: PUC, 2001.

PADDEN, CAROL "The deaf community and the culture of deaf people". In: WILCOX, S.

(Ed.) American Deaf Culture: na anthology. Burtonsville, MD: Lindtok Press, 1989

RABINOW, Paul. (1995), Artificialidade e iluminismo: da sociobiologia à biossociabilidade. In: Antropologia da razão. Rio de Janeiro, UFRJ.

SACKS, Oliver. Vendo Vozes: Uma Viagem ao mundo dos surdos. São Paulo: Companhia das Letras, 2002.

SKLIAR, Carlos. (org.) A surdez: um olhar sobre as diferenças. 2001 Porto Alegre, Editora Mediação, 2000.

STOKOE, W. Sign Language structure. Silver Spring, Maryland, Linstok Press, 1960.

TURNER, H . Graham "How is deaf culture? Another perspective on a fundamental concept". In Sign Language Studies, vol. 83, 1994

TYLOR, Edward B. Researches into the Early History of Mankind and the Development of civilization, London: John Murray, 1870

WILCOX S. \& WILCOX P. Aprender a ver. Rio de Janeiro, Editora Arara Azul, 2005

\section{NOTAS}

1. Para marcar ainda mais a diferença, convenciona-se grafar "surdo" com a primeira letra em caixa alta - Surdo - quando se quer referir não aos aspectos audiológicos, mas aos culturais ou políticos da condição de surdez.

2. Sobre cuja decisão pesou a influência de um oralista célebre, Alexander Graham Bell.

3. "Devido a uma mutação, um gene recessivo posto em ação pela endogamia, uma forma de surdez hereditária vingou por 250 anos na ilha de Marta's Vineyard, em Manhattan, a partir da chegada dos primeiros colonizadores surdos na década de 1680. Em meados do século XIX quase não havia famílias na porção norte da ilha que não fossem afetadas e em alguns povoados (Chilmark, West Tisbury) a incidência de surdez aumentara para uma em quatro pessoas. Em resposta a esta situação, toda a comunidade aprendeu a língua de sinais, havendo livre comunicação entre ouvintes e surdos. De fato, estes quase nunca eram vistos como 'surdos' e certamente não eram considerados de modo algum 'deficientes' " (Sacks, 2002 p. 45)

4. Como prova de que essa rede de interações não só é necessária, mas realmente é efetiva na formação da língua de sinais, cita-se o caso da Nicarágua: até a revolução sandinista, não havia no país uma só escola especial para surdos, para os quais não restava senão a comunicação utilizada no interior das famílias, limitada e restrita à esfera doméstica. Em 1979 as autoridades convidaram a lingüista norte-americana Judy Kegl para implantar escolas especiais para surdos e o resultado é que estes, reunidos e convivendo, deram início a um verdadeiro processo de "'invenção" de uma língua em sentido próprio, a "LSN", ou Lengua de Señas Nicaraguense, a partir dos sinais caseiros, mas organizados numa estrutura gramatical reconhecível.

5. Citado por Sacks (2002:87) . Cabe lembrar ainda o interesse despertado por relatos como o de Kaspar Hauser, de Anselm von Feuerbach, publicado em 1832. (idem,ib.: 64 e ss. ) sobre a questão da ausência de aquisição de linguagem. 
6. Parte dessa literatura, sobre educação, é denominada por Carlos Skliar de "Estudos surdos em Educação" (2001, p.6).

7. No entanto, ele é cuidadoso, sabe em que terreno está pisando: "Although this paper has been fairly severe in its criticism of some previous work in the field, it does so in the belief that the exercise may mark a step towards enriching our understanding of the fundamental issues raised. I make no claim whatsoever to expert knowledge in the fields of sociology and anthropology, having come to the problem from a sociolinguistic point of view, and look forward to reading more well-informed development of the issues raised." (op. Cit. 120). Maria Cecília Moura (2000) também reconhece a importância e as dificuldades envolvidas no uso do termo, mas termina empregando a expressão "Comunidades de Surdos de São Paulo" (p.71).

8. Tome-se, por exemplo, o caso do uso da categoria de "pedaço", que será apresentada mais adiante, em que se verifica a presença do núcleo de significado característico de comunidade. Assim, pode-se afirmar que há relações de tipo comunitário nessa forma de sociabilidade, encontro e uso do espaço, ainda que não se possa dizer que "pedaço" seja apenas uma outra maneira de designar "comunidade".

9. Ver Dos Santos et alii, 1978, Finep/Ibam, São Paulo, 1985.

10. Ver a propósito, Magnani, J.Guilherme: "O (velho e bom) caderno de campo", in Revista Sexta Feira, no 1, maio de 1997

11. Em estudos clássicos sobre estados de êxtase e possessão discute-se o papel da música, do ritmo, dos cânticos, louvações, etc. sobre a produção de estados alterados de consciência. É de perguntar-se que situação poderia produzir efeito similar numa pessoa surda: a profusão e intensidade dos sinais? As cores? A vibração sentida pelo corpo como um todo , como um receptor mais amplo e genérico?

12. E que se abrem para além dos limites de uma cidade, instaurando redes e fluxos mais amplos. 13. "Estudos da Comunidade Surda" - Diretório dos Grupos de Pesquisa no Brasil - CNPq. 